\title{
De Oliveira Silva, María Aparecida, Plutarco e Roma. O mundo grego no Império, São Paulo, Editora de Universidade São Paulo, 2014, 318 pp. $^{1}$
}

Antes de entrar de lleno a comentar la obra, es importante apuntar que este trabajo no es el único de la autora sobre Plutarco. ${ }^{2}$ Su interés la ha llevado a explorar el tema desde varios ángulos, consiguiendo ganarse merecido prestigio en América Latina como intérprete y promotora de un corpus literario complejo y apasionante. El acento que pone la profesora de Oliveira Silva deriva en la construcción de una lectura de recuento y articulación de elementos constitutivos de biografías y tratados antiguos, así como en la contribución a la crítica filológica e historiográfica plutarquianas de las últimas décadas. Los esfuerzos desarrollados en el libro que nos ocupa, así como en estudios previos, pretenden adentrarse en un discurso de gran sofisticación. Ya por la naturaleza propia de la fuente - es bien sabido

${ }^{1}$ Contenido del libro: "Prefacio", escrito por Fábio Vergara Cerqueira, pp. 11-15; "Introducción", pp. 17-25. Primera parte, "Plutarco e Roma", pp. 29-95; Segunda parte, "O mundo grego de Plutarco", pp. 99-199; Tercera parte, "O mundo grego no imperio", pp. 203-283. “Conclusões", pp. 285-290. "Bibliografía”, 291-318.

${ }^{2}$ Entre sus libros colectivos, son de mencionar: De Oliveira Silva, Chevitarese, Cornelli (orgs.), A Tradição Clássica e o Brasil, Brasília, Fortium/Archai-UnB, 2008; De Oliveira Silva, Funari (orgs.), Política e Identidades no Mundo Antigo, São Paulo. Annablume/ Fapesp, 2009; De Oliveira Silva, Cerqueira (eds.), Ensaios sobre Plutarco. Leituras Latino-Americanas, Pelotas, Edufpel, 2010; De Oliveira Silva, Pozzer, Porto (orgs.), Um Outro Mundo Antigo. São Paulo, Annablume/Fapesp, 2013; De Oliveira Silva, Leão, Cardó (coords.), Plutarco entre Mundos: Visões de Esparta, Atenas e Roma, Coimbra, Imprensa da Universidade de Coimbra/Annablume, 2014. Entre sus libros individuales, destaca: Plutarco Historiador: Análise das Biografias Espartanas, São Paulo, Edusp, 2006; y entre sus traducciones: Plutarco, Da Malícia de Heródoto, São Paulo, Edusp/Fapesp, 2013. 
que Plutarco es difícil de leer en lengua griega-; dado que los giros lingüísticos, recursos estéticos, retóricos y poéticos, exigen gran habilidad del lector. Ya por la época histórica en la que vivió el de Queronea, un período de intenso intercambio entre los pueblos del mundo antiguo, durante el cual pervivieron tradiciones griegas modificadas con el paso de los siglos. Con frecuencia, la época de dominación romana sobre la Hélade es subestimada por compararla, sin mayor examen, con temas, autores y movimientos de la Edad Clásica que, obviamente, tienen una naturaleza diferente. Así, pues, los acontecimientos de un lapso tan importante se minimizan omitiendo aspectos históricos sin los que no podrían concebirse siquiera las proyecciones del "clasicismo" griego en la Antigüedad Tardía y la Edad Media. Uno de los tópicos mejor cuidados de Plutarco $e$ Roma es la problematización sobre la existencia de una cultura grecorromana en tanto que microcosmos con una dinámica exegética particular.

La introducción y el primer capítulo marcan la pauta a seguir en el resto del libro. Allí se exponen algunas ideas exegéticas fundamentales, mismas que son revisadas a la luz de trabajos previos sobre Plutarco y el mundo grecorromano. De Oliveira Silva se vale de una sólida metodología analítica que sopesa las contribuciones de distintos especialistas con mesura y rigurosidad. Con quienes discrepa, lo hace mediante argumentos bien expuestos; con los que concuerda, lo hace compartiéndonos coincidencias y diferendos. Gracias a la compilación razonada de investigaciones sobre Plutarco, es posible tener acceso a un mapa en el que se muestra los caminos ensayados con anterioridad. La selección bibliográfica que se hizo para lograr tal propósito es pertinente y actualizada. Se consigue un diálogo nutrido porque el acervo consultado fomenta un estudio dinámico que explora diferentes perspectivas de la misma cuestión, este detalle enriquece significativamente los horizontes del libro.

La profesora de Oliveira Silva establece directrices generales para fincar un armazón hermenéutico diseñado para adentrarse en diversas áreas. La que se identifica con mayor facilidad es la sociopolítica, que se pone de manifiesto en la ocupación romana de Grecia. Sin embargo, las condiciones en que dicha intervención se produjo son observadas con gran cuidado para entresacar las implicaciones que tuvo en la vida y pensamiento tanto de griegos como de romanos. La organización de territorios, regidos bajo el esquema de colonias, fue muy dispar en diferentes latitudes, aún en el interior mismo de la Hélade. Estos detalles exigen de un bordado fino por parte del investigador, una visión minuciosa que no se pierda en banalidades y que, simultáneamente, no desdibuje la totalidad. El campo lingüístico es también abordado con igual seriedad. La obra plutarquiana, en especial 
Vidas paralelas, además de ser tratada en términos de literatura que registra el sentimiento, creencias e ideas de una época, también es leída bajo la posibilidad de ser el manifiesto que expresa la identidad griega a través del legado ancestral conservado mediante la lengua. La ética y la religión perviven en el medio perfecto para sobrellevar el paso de los siglos y florecer en un momento en el que tanto se necesitaba cohesión espiritual en torno a valores culturales. Mediante la articulación de los aspectos sociopolíticos con los lingüísticos, logra llegarse al entendimiento de lo antropológico, cuya expresión más acabada será la idea de identidad helena frente al imperio. La crítica no ha logrado consensuar su opinión sobre Plutarco a lo largo de los siglos. Algunos afirman que la extensa obra de este hombre no es otra cosa más que un esfuerzo metódico - poco original - por compilar lo hecho por los grandes maestros de antaño, constituyendo un extenso y complicado apéndice de la Época Clásica, especialmente de la Academia. Mientras, otros conciben el trabajo de este hombre como uno de las grandes colecciones que la Antigüedad legó a la literatura universal; estableciendo Plutarco el camino a seguir en la elaboración de la biografía como género literario e histórico, ${ }^{3}$ constituyendo asimismo una de las pocas fuentes esenciales para recibir la visión de la teología y filosofía egipcias, conservadas por el tamiz del neoplatonismo. La religión es vista en términos de fenómeno social vigente en la cotidianidad de los griegos, pero, además, como conjunto de ideas en las que se agrupan indisolublemente la tradición, el mito, la filosofía y la historia.

En este libro, así como en varias de sus demás publicaciones, la profesora de Oliveira se pregunta dentro del proceso de investigación ¿qué era Plutarco?, ¿historiador?, ¿literato?, ¿filósofo?, ¿gramático? Nos brinda respuestas parciales no por desconocimiento, tampoco por anhelar fragmentar la compleja unidad del quehacer intelectual de un hombre con miras puestas muy lejos y muy alto, sino porque la naturaleza particular de los estudios

\footnotetext{
${ }^{3}$ A. R. Littlewood ("Biography and Autobiography", en la Encyclopedia of Greece and Hellenic Tradition I, London, Fitzroy Dearborn Publishers, 2000, pp. 227-231) señala el uso de algunas biografías de Vidas paralelas para enseñar conceptos gramaticales y éticos a los niños bizantinos. Görgemanns ("Biographie", en Neue Pauly Enzyklopädie der Antike, Verlag J. B. Metzler, Stuttgart, 1997, pp. 88-97) apunta que Plutarco es quien establece la estructura narrativa de la personalidad para construir biografías, además de considerarlo, al lado de Polibio, uno de los pilares teoréticos del género biográfico, complementando la iniciativa literaria con su gran erudición del folklore griego. Carl Adresen ("Biographie", en Lexikon der antike Welt, München, Artemis Verlag, 1965, pp. 470-473) considera Vidas paralelas una obra única en su tiempo, en la que se reúnen los aspectos esenciales de la biografía helenística activados a partir de conceptos aristotélicos.
} 
que ha emprendido así lo exige. ${ }^{4}$ Preguntarse por la naturaleza de la obra de Plutarco es una herramienta metodológica de utilidad suma, indispensable para aproximarse al sentido originario de las palabras y los discursos.

Uno de los principios interpretativos del estudio se establece desde las primeras páginas:

[...] torna-se infrutífero pensar a obra de Plutarco sem considerar sua formação grega, não apenas no aspecto literário, mas também na de seu caráter e em seu modo de interpretar o mundo. A postura mais común nas análises de seus textos é a ênfase apenas na dependencia grega de política e da economía romanas e da demostração de como os intelectuais gregos da época reagiam da diante da dominaçao romana, em geral, vistos como parte da política imperial. (p. 31)

Dicho sistema para interpretar el mundo es templado por el contexto que lo vio nacer, es decir, la literatura de Plutarco es un espacio inspirado y dirigido por la realidad que pretende captar; pero, simultáneamente, las circunstancias que le sirven de soporte, directriz e influjo son exhibidas. Lo que se calla e insinúa, aquello que no se explica porque es tan cotidiano y natural para la época que no merece mayor puntualización, es un nicho bien explorado por de Oliveira. Uno de los objetivos del libro es descubrir el ambiente histórico que envolvía las complejas relaciones de Roma con Grecia. Tebas, Atenas y Esparta eran más que regiones, momentos de la identidad helena en los que se vivía la historia y el sentimiento de pertenencia de formas diferentes. Dicha identidad tenía como uno de sus capítulos de mayor trascendencia la posición política del griego ante el imperio, otros capítulos eran la consciencia histórica de cada habitante de la Hélade sobre su pasado, así como la concepción que se tenía de Grecia y lo griego frente a la humanidad. Esa dinámica socio-antropológica queda lejos de nuestro entendimiento, aquí la autora concentra sus empeños en encontrar puntos para fundamentar la comprensión de las cosas. Respecto al tema de la identidad griega en el mundo imperial:

${ }^{4}$ En Plutarco historiador, concretamente en el capítulo "Biografía e História em Plutarco", pp. 35-67, de Oliveira medita sobre los ingredientes que integran el quehacer histórico del de Queronea, v. gr. la manera en que la historia imperial, regional o la historia de las religiones contribuían en la redacción de sus textos. Comenta: "Com a leitura de todas as biografías, entende-se a metodología utilizada por Plutarco em suas narrativas e notase que, embora a estatura geral corresponda à do gênero biográfico, em seu contenúdo encontramos a trabalho de investigção e de reflexão que são peculiares, ao historiador. Logo, como vemos, Plutarco não escreveu apenas biografías, mas um tipo de História, uma história subjacente, que é a das cidades-estados de sus biografados", p. 57. 
A construção de um sentimiento de pertença oa mundo de Homero, Hesíodo, Heródoto e Tucídides, enfim, das ciudades-estado. Falamos em uma identidade grega, pois dada a naturaleza monolítica da cultura grega em Plutarco, as variações são colocadas no plano das habilidades técnicas [...] os atenienses sao mais artísticos do que os espartanos, mas Plutarco ressalta a preferencia espartana pela música, ou seja, demostra a face artística espartana e, dessa maneira, salienta características comuns a ambos para a edificação de uma identidade grega, definida por suas prácticas, não pela geografía. Portanto, não importa a origen étnica do indivíduo, e sim seu conhecimento das práticas e dos costumes gregos. (p. 83)

La admiración de macedonios y romanos por la Hélade suele entorpecer las reconstrucciones de la política imperial de la Antigüedad. La alta estima que se tenía por la literatura, la historia, la música, ${ }^{5}$ la retórica, las ciencias, las religiones y la filosofía, en una palabra, por la paideía, no logra siempre ensamblar con la postura dominante adoptada por los conquistadores. Por tal razón, la auscultación del sentimiento "nacional" de los griegos que vivieron en estas etapas no cala hondo porque se asume, con gafas románticas, que fueron una colonia de excepción. Sin embargo, habría que comprender cómo concebían la dignidad de los griegos los generales, los senadores romanos, los emperadores, los mercaderes que llegaban a una tierra dominada, los colonos, los "urbanizadores" imperiales, hasta los soldados de más bajo rango de la tropa. Como en toda sociedad viva, la discrepancia define la forma en que cada uno experimenta la cotidianidad. La profesora de Oliveira Silva explora opiniones y posicionamientos de ambos lados, romanos y griegos pensaban su relación en una enorme gama de variables, ${ }^{6}$ empero, según la interpretación de la autora, Plutarco crea una literatura de resistencia. Si bien, hay una tradición contemporánea, no del todo nueva, que así lo visualiza, podemos decir que la argumentación esgrimida por de Oliveira brinda aportaciones importantes a esta línea de trabajo.

Aunque Plutarco se veía a sí mismo como parte del mundo grecorromano, no por ello renunciaba a las fuertes raíces que lo definían a él y a su pueblo. Su resistencia se produjo a través de la preservación de lo griego en

\footnotetext{
${ }^{5}$ Entendida simultáneamente en sus tres acepciones antiguas, a saber: arte de combinar los sonidos con el tiempo, componente esencial de la poesía y principio de orden.

${ }^{6}$ Téngase por botón de muestra la narración histórica de la fundación de Roma. El primer griego en tocar el tema, hasta donde sabemos, fue Diocles de Pepareto (s. v a. C.), mientras que el primer romano fue Fabio Píctor (s. III a. C.). Cabe destacar que Vida de Rómulo, texto en que aborda el asunto, fue escrito en griego. La fundación de Roma era, pues, un tópico obligado para ser estudiado tanto por el imperio como por las colonias; es en los sesgos que cada parte le daba, donde pueden comprenderse algunos aspectos culturales de la época.
} 
todas sus manifestaciones. La persona-héroe es el punto donde convergen valores y tradiciones. No fue casualidad que Licurgo, Solón y Demóstenes se tornaran en objeto de cuidadosas biografías escritas para mostrar una ventana al grandioso pasado griego. El de Queronea posiblemente dirigía sus obras a un amplio y heterogéneo público, compuesto por letrados, generales y otros militares de alto rango, así como por políticos. Sus lectores estaban esparcidos tanto por Roma como por Grecia. Hablar de los grandes legisladores, ponía al descubierto los valores de la Hélade, apoyados en antecedentes muy lejanos que se conectaban con los ideales que dieron la victoria a los aqueos en Troya, que permitieron vencer a los persas e hicieron de su patria la cuna de la más refinada civilización. Convicciones que, obviamente, no contaban por necesidad con un sustrato histórico que las validara, no obstante, nutrían el sentimiento de pertenencia de muchas personas. Vidas paralelas llevaba a los lectores a concluir, racionalmente, que los griegos eran herederos de un tesoro inaccesible para los romanos, siendo los responsables directos de crear un mundo civilizado. De Oliveira Silva llega a la siguiente conclusión:

[...] a visão de que Plutarco funde a cultura graga à romana, sugerindo a formação do povo greco-romano, mostra-se incosistete em vista do grande valor que ele atribuí aos hábitos gregos, como a religião, a filosofía e a literatura de Plutarco. A visão plutarquiana da história grega apresenta reflexões sobre o pasado e o presente dos gregos no Império Romano. Plutarco mune-se dos fatos e de seu sentimento de pertença a uma cultura dominada e idealizada a história grega ao retratar uma Grécia poderosa que promove, ao longo dos séculos, sua propia destruição. Notamos aquí o sentimento de superioridade racil em Plutarco, uma vez que não foram os macedônios ou romanos que derrotaram Grécia [...] A identidade grega construída por Plutarco completa seu quadro idelizado Grécia e dos gregos. (p. 287)

El libro que nos ocupa es un buen recurso para acercarse a la Hélade de forma más crítica y consciente. La problematización del período imperial podría replicarse con adecuaciones en el estudio de la dominación persa, los Ptolomeos en Egipto o del mundo bizantino, períodos que ofrecen multitud de dificultades para los investigadores. María de Oliveira Silva nos ofrece un trabajo que invita a pensar la Antigüedad como un mundo en movimiento, más que a contemplarlo sin asumir alguna actitud. 